\title{
One Pot Green Synthesis of Pyrazolo[4, 3- $d$ ]pyrimidin- 7(4H)-ones and Dihydroquinazolin-4(1H)-ones Derivatives Catalyzed by Efficient Recyclable Amberlite IR-120H Resin
}

\author{
ISMAIL $^{1}$, GANGADHAR THALARI $^{2}$, \\ TASNEEM MOHAMMED $^{3}$ and BHASKAR KUTHATI ${ }^{1 *}$
}

${ }^{1}$ Department of Chemistry, Osmania University, Hyderabad-500007, India

${ }^{2}$ Department of Chemistry, Nizam College, Osmania University, Hyderabad-500001, India

${ }^{3}$ IbnSina National College for Medical Studies, Jeddah-21418, Kingdom of Saudi Arabia bkuthati@gmail.com

Received 10 May 2016 / Accepted 3 June 2016

\begin{abstract}
Cyclic condensation reactions of various aromatic and heterocyclic aldehydes have been carried out with 4-amino-1-methyl-3-propyl-1 $H$-pyrazole-5-carboxamide and $o$-aminobenzamide by using Amberlite IR-120H resin to afford the corresponding pyramidin-ones and quinazolin-ones in good yield. Further it is of interest to note that cyclisations in catalyzed media are dramatically accelerated to afford pyrazolo[4,3-d] pyrimidin-7(4H)-ones and dihydroquinazolin-4(1H)-ones. This procedure works efficiently in various concentrations of amberlite IR-120H resin and different solvent media under reflux conditions. In the end the catalyst has been recovered and reused up to four cycles without significant loss of activity.
\end{abstract}

Keywords: 5-Arylpyrazolo[4,3-d]pyrimidin-7(4H)-ones, 2-aryldihydroquinazoline-4(1H)-one, 4-amino1-methyl-3-propyl-1 $H$-pyrazole-5-carboxamide, $o$-aminobenzamides and amberlite IR-120H resin

\section{Introduction}

Quinazolinones are a class of compounds with a significant heterocyclic core ${ }^{1}$ endowed with a diverse wide range of biological properties and pharmaceutical activities ${ }^{2}$ like anti-cancer, sedatives, anti-inflammatory and anti-convulsants. Furthermore, the quinazolinone skeleton is frequently found in various natural products ${ }^{3}$. Despite the fact that a large number of publications describing the condensation reactions are available, the synthesis of pyrimidinones and quinazolin-ones has remained almost unexplored. Pyrazole being heterocyclic planar five membered rings have various pharmacological activities. These versatile compounds have been used for designing potent bioactive agents (Figure 1) such as antimicrobial $^{4}$, anti-inflammatory ${ }^{5}$, anticancer ${ }^{6}$, antioxidant ${ }^{7}$ and herbicidal ${ }^{8}$. In this regard 
many attempts have been carried out to synthesize quinazolin-ones ${ }^{9}$. Earlier works ${ }^{10}$ report the synthesis by condensation of $o$-aminobenzamides with aldehydes or ketones in presence of expensive catalysts like gallium(III)triflate ${ }^{11}$, zinc(II) perfluorooctanoate ${ }^{12}$, amberlyst- $15^{13}$, molecular iodine ${ }^{14-16}$. However many of these methods suffer from harsh reaction conditions, low product yield, prolonged reaction times and toxic organic catalysts. Considering the above problems and in continuation of our endeavor towards the development of eco-friendly synthetic protocols for heterocyclic compounds, it was thought worthwhile to develop a novel, simple, greener and expeditious route for obtaining 2,3dihydroquinazolin-4(1H)-one derivatives. 2,3-dihydroquinazolin-4(1H)-ones have been very attractive targets in synthetic chemistry in recent years because of their biodynamic and pharmacological properties (Figure 1).<smiles>Cc1ccccc1N1C(=O)c2cc(S(N)(=O)=O)c(Cl)cc2NC1C</smiles>

Metolazone<smiles>CCC1NC(=O)c2cc(S(N)(=O)=O)c(Cl)cc2N1</smiles>

Quinethazone<smiles>CN1c2ccccc2C(=O)N2CCc3c([nH]c4ccccc34)C21</smiles>

Evodiamine<smiles>CCCc1nn(C)c2c(=O)nc(-c3cc(S(=O)(=O)N(C)CCC4CCCN4C)ccc3OCC)[nH]c12</smiles><smiles>O=C1NC(c2ccccc2)Nc2cc(Cl)c([N+](=O)[O-])cc21</smiles>

Fenquizone<smiles>CCCc1nn(C)c2c(=O)[nH]c(-c3cc(S(=O)(=O)N4CCN(C)CC4)ccc3OCC)nc12</smiles><smiles>CCOc1ncc(S(=O)(=O)N2CCN(CC)CC2)cc1-c1nc2c(CC)n(CCOC)nc2c(=O)[nH]1</smiles><smiles>CCCc1nn(C)c2c(=O)nc(-c3cc(S(=O)(=O)N4CCN(CCO)CC4)ccc3OCC)[nH]c12</smiles><smiles>CCC(Nc1ncnc2nc[nH]c12)c1nc2cccc(F)c2c(=O)n1-c1ccccc1</smiles>

Idelalisib

Figure 1. Pyrazolo[4,3-d]pyrimidin-7(4H)-ones and dihydroquinazolin-4(1H)-one, skeleton containing bioactive molecules

In recent years there has been more interest in green synthetic routes for its synthesis ${ }^{17-19}$. Use of solid resin catalyst has proven to be superior over the conventional catalytic methods due to inexpensive and non-toxic nature of the catalysts used. Amberlite IR-120H is one of the best examples of heterogeneous, ecofriendly catalyst for chemical transformations. In continuation with our research we have developed a one pot synthesis of pyrazolo[4,3d]pyrimidin-7(4H)-ones and dihydroquinazolin-4(1H)-one, by condensation of 4-amino-1methyl-3-propyl-1 $H$-pyrazole-5-carboxamide and $O$-aminobenzamide with various aldehydes using recyclable, benign and inexpensive amberlite IR-120H resin ${ }^{20}$.

\section{Experimental}

All the reactions, unless otherwise stated, were monitored by thin layer chromatography (TLC) on silica gel plates (60 F254), visualizing with ultraviolet light or iodine. NMR spectra were recorded on Varian $400 \mathrm{MHz}$ instrument in $\mathrm{CDCl}_{3}$ and DMSO-d6 solvents. 
Proton chemical shifts are given in $\delta$ relative to tetramethylsilane $(\delta 0.00 \mathrm{ppm})$ in $\mathrm{CDCl}_{3}$ or in DMSO-d6 $(\delta 2.50 \mathrm{ppm})$. Carbon chemical shifts are internally referenced to the deuterated solvent signals in $\mathrm{CDCl}_{3}(\delta 77.1 \mathrm{ppm})$ or in DMSO-d6 $(\delta 39.5 \mathrm{ppm})$ expressed in parts per million $(\delta)$ downfield from $\mathrm{Me}_{4} \mathrm{Si}$. Spin multiplicities are given as s (singlet), $\mathrm{d}$ (doublet), t (triplet) and $\mathrm{m}$ (multiplet) as well as b (broad). Coupling constants (J) are given in hertz. Melting points were determined by using a Buchi melting point B-540 apparatus. High-resolution mass spectra were recorded on a Waters QTOF mass spectrometer.

\section{General procedure for the preparation of compounds $(\mathbf{3 a - j})$}

A mixture of aromatic or heterocyclic aldehydes (2a-j) (1.0 mmol) and 4-amino-1-methyl-3propyl-1H-pyrazole-5-carboxamide $1 \mathbf{1 a}(1.0 \mathrm{mmol})$ in acetonitrile $(5.0 \mathrm{~mL})$ at room temperature Amberlite IR-120H resin $(20 \mathrm{~mol} \%)$ was added. The reaction mixture was stirred until the completion of the starting materials as indicated by TLC. The reaction mixture was filtered and solvent was evaporated and the crude product was triturated with methyl tert-butyl ether (MTBE) to obtain the pure product 3a-j. The product was identified by ${ }^{1} \mathrm{H}$ NMR, ${ }^{13} \mathrm{C}$ NMR and HRMS.

\section{General procedure for the preparation of compounds (5a-g)}

A mixture of aromatic or hetero cyclic aldehydes $\mathbf{2 a - g}(1.0 \mathrm{mmol})$ and $o$-aminobenzamide $4 \mathbf{a}(1.0 \mathrm{mmol})$ in acetonitrile $(5.0 \mathrm{~mL})$ at room temperature Amberlite IR-120 $\mathrm{H}$ resin $(20$ mol\%) was added. The reaction mixture was stirred until the completion of the starting materials as indicated by TLC. The solvent was evaporated and the crude product was triturated with methyl tert-butyl ether (MTBE) to obtain the pure product 5a-g. The product was identified by ${ }^{1} \mathrm{H} \mathrm{NMR},{ }^{13} \mathrm{C}$ NMR and HRMS.

\section{Results and Discussion}

At the outset 4-amino-1-methyl-3-propyl-1H-pyrazole-5-carboxamide and $o$-aminobenzamide were condensed with aldehydes with and without solvent and catalyst. It was observed that the reaction was sluggish with low yield (Table 1, entry 1). In order to optimize the reaction conditions the synthesis was carried out using various solvents such as toluene, 1,4-dioxane, $\mathrm{CH}_{2} \mathrm{Cl}_{2}$, Dichloroethane (DCE), DMSO, DMF, MeCN, MeOH and EtOH using amberlite ir$120 \mathrm{H}$ acidic resin as a recyclable catalyst (Table 1, entries 2-10). Gratifyingly, a marked increase in the yield and shorter reaction time was observed when $\mathrm{MeCN}$ was used as solvent at room temperature (Table 1, entry 8 ). The desired products obtained were isolated in excellent yields and characterized as pyrazolo[4,3-d]pyrimidin-7(4H)-ones and dihydroquinazolin-4(1H)-ones respectively from spectral analysis $\left({ }^{1} \mathrm{H},{ }^{13} \mathrm{C}\right.$ NMR and HRMS).

The methodology was further explored using different amounts of catalyst Amberlite IR- $120 \mathrm{H}$. It is noteworthy that when the amount of catalyst was increased from $5 \mathrm{~mol} \%$ to $15,20,30$ and $40 \mathrm{~mol} \%$ the yields increased from $60 \%$ to $80,95,95,95 \%$ respectively (Table 2, entries 1-5). Further increase in the concentration did not have any profound effect on the reaction yield (Table 2, entry5). $20 \mathrm{~mol} \%$ of the catalyst emerged as the most effective concentration in producing the highest yield (Table 2, entry 4). Therefore, it can be concluded that the optimum conditions required for the smooth condensation of the reactants is by using $\mathrm{CH}_{3} \mathrm{CN}$ as solvent and $20 \mathrm{~mol} \%$ Amberlite IR-120H catalysts at room temperature.

The transformations were now performed using various substituted aromatic and heterocyclic aldehydes with 4-amino-1-methyl-3-propyl-1H-pyrazole-5-carboxamide and $o$-aminobenzamide under optimized reaction conditions. The reactions occurred smoothly 
furnishing the products in good to excellent yields (Scheme 1, Table 3, entries 1-11) and (Scheme 2, Table 4, entries 1-7) respectively. The presence of electron donating and withdrawing groups on aromatic aldehydes such as $-\mathrm{NO}_{2},-\mathrm{OCH}_{3},-\mathrm{CN},-\mathrm{Br},-\mathrm{Cl},-\mathrm{OEt},-\mathrm{OH}$ was also well established to afford the corresponding products smoothly with good yield.

The most plausible mechanistic pathway for the formation of quinazolin-ones Scheme 1 is as shown in Figure 2. Amberlite IR-120H is believed to protonate the carbonyl oxygen to form (I) which is prone to nucleophilic attack from the diamino group to form (II). This species loses a water molecule to form a stable product (III). Nucleophilic attack by the second amino group results in cyclization to form the product quinazolin-ones (V).

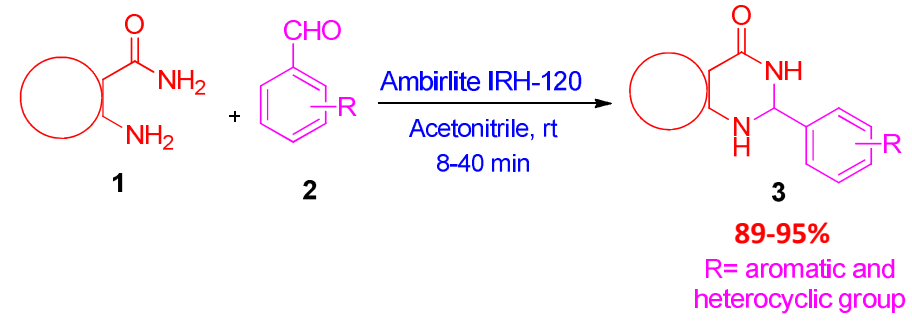

Scheme 1. Amberlite IR-120H catalyzed synthesis of pyrazolopyrimidin-one and dihydroquinazolin-ones

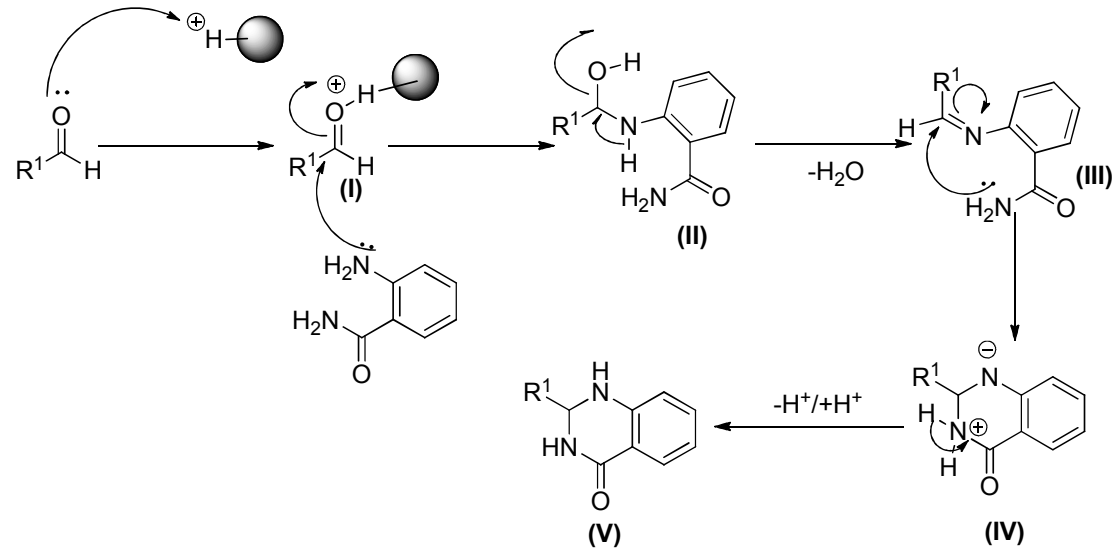

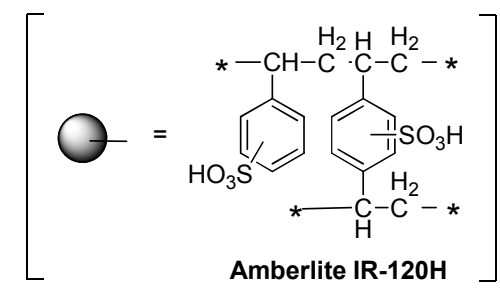

Figure 2. Possible mechanism of synthesis of dihydroquinazolinone

Although earlier procedures have reported the synthesis of quinazolinones in good yields, our methodology has the advantage as it does not require presence of either inert or anhydrous atmosphere, low temperature condition, less reaction time needed for condensation of 4-amino-1-methyl-3-propyl- $1 \mathrm{H}$-pyrazole-5-carboxamide and $\mathrm{o}$-aminobenzamide with aldehydes to the quinazolinone derivatives. 
We next explored the reusability of amberlite IR-120H which is the highlight of this reaction. The catalyst was isolated from the reaction mixture four times (Table 5, entries 1-4) and could be reused without significant loss of activity. Initially $20 \mathrm{~mol} \%$ of catalyst was used which was successfully isolated and recycled at 19,18 and $16 \mathrm{~mol} \%$ in the next consecutive three cycles giving excellent yields ranging from $95 \%$ to $93,91,87 \%$ respectively (Figure 3 ).

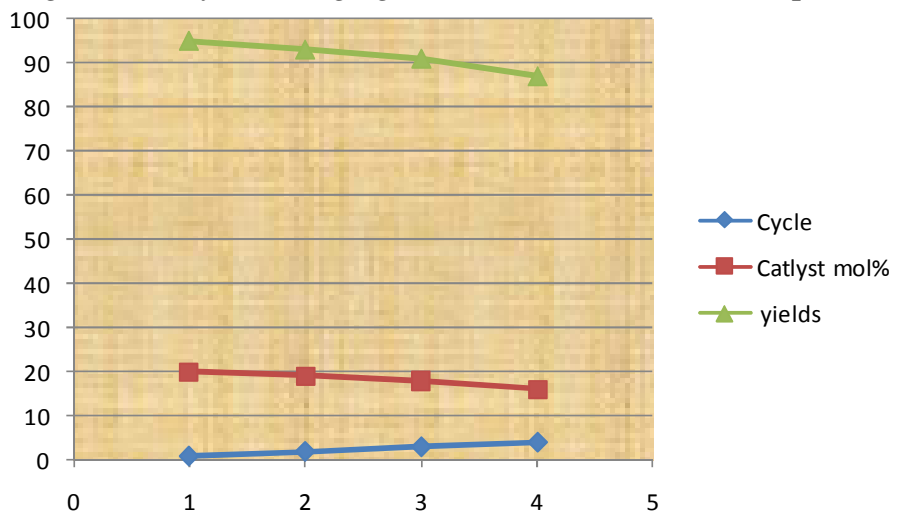

Figure 3. Reusability of Amberlite IR-120H for synthesis of 3a

It was interesting to note that the present process did not require chromatographic purification technique. The product could be isolated by filtration. The solid was triturated with methyl tert-butylether (MTBE) and filtered to give the pure pyrazolopyrimidinone and dihydroquinazolinone derivatives. The products were characterized by ${ }^{1} \mathrm{H}$ NMR, ${ }^{13} \mathrm{C}$ NMR and HRMS.

Table 1. Optimisation of reaction condition for the synthesis of 3a with $1 \mathbf{a}$ and $\mathbf{2 a}$ in the presence of Amberlite IR-120H

\begin{tabular}{ccccc} 
& & & \\
& & & & 32 \\
\hline
\end{tabular}

${ }^{a}$ All reaction were carried out using 20 mol\% of Amberlite IR- $120 \mathrm{H}$ at various condition. ${ }^{b}$ Isolated yields. ${ }^{c}$ Reaction carried out absence of catalyst and solvent. ${ }^{d}$ Catalyst were recovery and reused for same reaction and corresponding yields 
Table 2. Screening of the catalyst amberlite ir- $120 \mathrm{H}$ at various mole $\%$

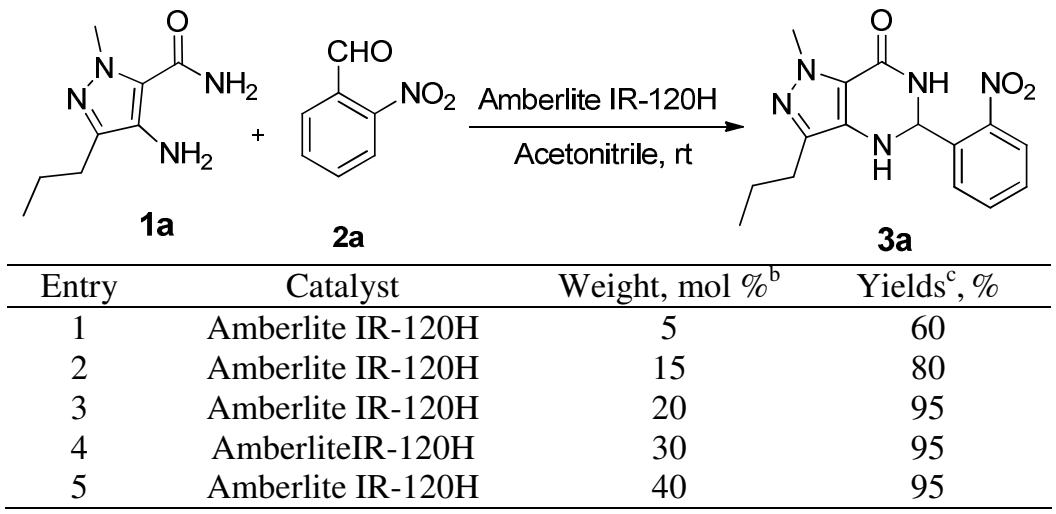

${ }^{a}$ Reaction condition: all the reaction were carried out by using 4-amino-1-methyl-3-propyl-1Hpyrazole-5-carboxamide (1 mmol), 2-nitro benzaldehyde $(1.0 \mathrm{mmol})$ in acetonitrile at room temperature for 10 mins. ${ }^{b}$ Amberlite IR- $120 \mathrm{H}$ in various mol\%. Isolated yields

Table 3. Synthesis of pyrazolo[4,3- $d]$ pyrimidin-7(4H)-ones (3a-3j) from 4-amino-1-methyl3-propyl-1 $H$-pyrazole-5-carboxamide (1a) and aldehydes $(\mathbf{2 a - 2} \mathbf{j})^{\mathrm{a}}$<smiles>[R]C=O</smiles>

$1 \mathrm{a}$
Amberlite ir-120H

$\mathrm{CH}_{3} \mathrm{CN}, \mathrm{rt}$ $8-30 \mathrm{~min}$ $89-95 \%$

$\begin{array}{cccccc}\begin{array}{c}\text { Entry } \\ (\mathbf{1 a})\end{array} & \mathrm{R}-\mathrm{CHO}(\mathbf{2 a - j}) & \text { \% } \\ \mathrm{Yields}^{\mathrm{b}}\end{array}$




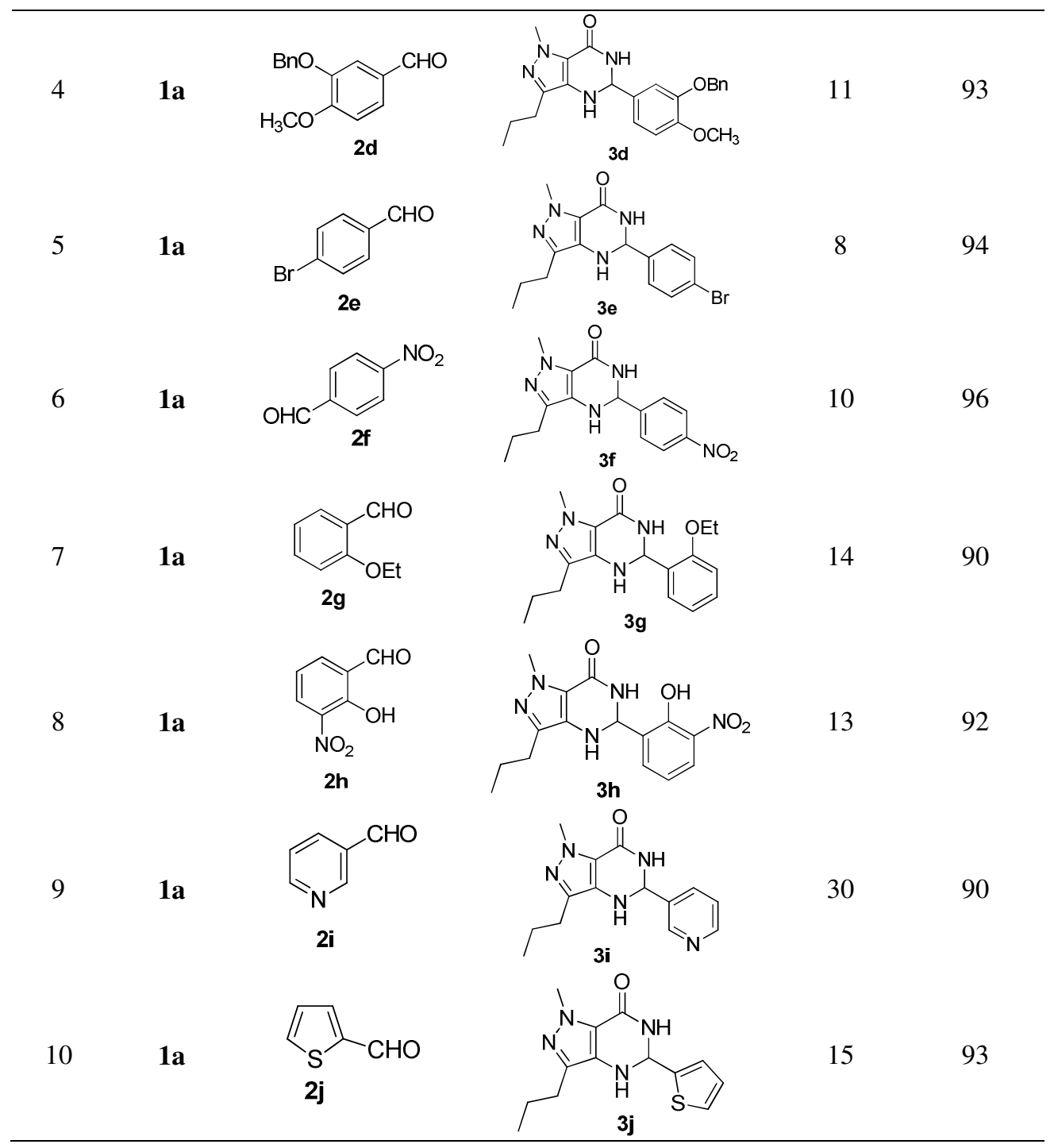

${ }^{a}$ Reaction condition: all the reaction were carried out by using 4-amino-1-methyl-3-propyl-1Hpyrazole-5-carboxamide $(1 \mathrm{mmol})$, aldehydes $(1.0 \mathrm{mmol})$ and $20 \mathrm{~mol} \%(\mathrm{wt} / \mathrm{wt})$ amberlite $I R-120 \mathrm{H} \mathrm{in}$ acetonitrile at room temperature. ${ }^{b}$ Isolated yields

Table 4. Synthesis of dihydroquinazolin-ones (5a-5g) from $o$-amino benzamide (4a) and aldehydes (2a-g) ${ }^{\mathrm{a}}$

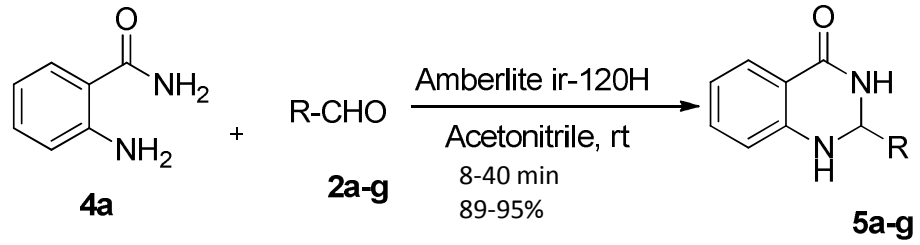




Entry Reactant (4a)

${ }^{a}$ Reaction condition: all the reaction were carried out by using 2-aminobenzamide $(1 \mathrm{mmol})$, aldehydes $(1.0 \mathrm{mmol})$ and $20 \mathrm{~mol} \%(\mathrm{wt} / \mathrm{wt})$ amberlite $\mathrm{ir}-120 \mathrm{H}$ in acetonitrile at room temperature. ${ }^{b}$ Isolated yields

Table 5. Recyclability of amberlite IR-120H resin<smiles>CCCc1nn(C)c(C(N)=O)c1NC1NC(=O)c2c(CCC)nn(C)c2C1c1ccccc1[N+](=O)[O-]</smiles>

2a 


\begin{tabular}{ccc}
\hline Cycle & Amberlite IR-120H, mol \% & Yields $^{\mathrm{b}}, \%$ \\
\hline 1 & 20 & 95 \\
2 & 19 & 93 \\
3 & 18 & 91 \\
4 & 16 & 87 \\
\hline
\end{tabular}

${ }^{a}$ Reaction condition: all the reaction were carried out by using 4-amino-1-methyl-3-propyl-1Hpyrazole-5-carboxamide (1 mmol), 2-nitro benzaldehyde $(1.0 \mathrm{mmol})$ in acetonitrile at room temperature for 10 mins. ${ }^{b}$ Recovered catalyst used in various mol\%. ${ }^{c}$ Isolated yields

\section{Conclusion}

In conclusion, we have developed an operationally simple, and clean procedure for the synthesis of 5-arylpyrazolo[4,3-d]pyrimidin-7(4H)-ones and 2-aryl-2,3-dihydroquinazolin$4(1 \mathrm{H})$-one derivatives using $20 \mathrm{~mol} \%$ amount of recyclable amberlite IR-120H resin. The notable features of the present method are mild reaction conditions, recyclability, ecofriendly, readily available inexpensive metal free reagents, excellent yield and simple workup that make it an economically viable and attractive protocol for the synthesis of biologically important heterocycles.

\section{Acknowledgment}

The author Ismail is thankful to the Osmania University and CFRD for providing necessary facilities.

\section{References}

1. (a) Hess H J, Cronin $\mathrm{T} \mathrm{H}$ and Sciabine A, J Med Chem., 1968, 11, 130-136; DOI:10.1021/jm00307a028 (b) Saxena S, Verma M, Saxena A K and Shanker K, Indian J Pharm., 1991, 53, 48.

2. Padia J K, Field M, Hinton J, Meecham K, Pablo J, Pinnock R, Roth B D, Singh L, Chauhan N S, Trivedi B K and Webdale L J Med Chem., 1998, 41(7), 1042-1049; DOI:10.1021/jm970373j

3. Welsch M E, Snyder S A and Stockwell B R, Curr Opin Chem Biol., 2010, 14(3), 347-361; DOI:10.1016/j.cbpa.2010.02.018

4. Singh T, Srivastava V K, Shalabh S and Ashok Kumar, Indian J Chem., 2006, 45, 2558-2565.

5. Xia Y, Yang Z Y, Hour M J, Kuo S C, Xia P, Bastow K F, Nakanishi Y, Nampoothiri P, Hackl T, Hamel E and Lee K H, Bioorg Med Chem Lett., 2001, 11(9), 1193-1196; DOI:10.1016/S0960-894X(01)00190-1

6. Kenichi O, Yoshihisa Y, Toyonari O, Toru I and Yoshio I, J Med Chem., 1985, 28(5), 568-576; DOI:10.1021/jm50001a006

7. Asif M, Int J Med Chem, 2014, 395637; DOI:10.1155/2014/395637

8. Wang D W, Lin H Y, Cao R J, Ming Z Z, Chen T, Hao G F, Yang W C and Yang G F, Pest Manag Sci., 2015, 71(8), 1122-1132; DOI:10.1002/ps.3894

9. (a) Murthy P V N S, Rambabu D, Rama Krishna G, MallaReddy C, Prasad K R S, Basaveswara Rao M V and Pal M, Tetrahedron Lett., 2012, 53(7), 863-867; DOI:10.1016/j.tetlet.2011.12.023 (b) Chen J, Su W, Wu H, Liu M and Jin C, Green Chem., 2007, 9, 972-975; DOI:10.1039/B700957G (d) Shaabani A, Maleki A and Mofakham H, Synth Commun., 2008, 38(21), 3751-3759; DOI:10.1080/00397910802213802 
10. Guggenheim K G, Hannah T and Kurth M J, Org Lett., 2012, 14(14), 3732-3735; DOI:10.1021/ol301592z

11. Wang L M, Hu L, Shao J H, Yu J J, Zhang L, J Fluorine Chem., 2008, 129(12), 11391146; DOI:10.1016/j.jfluchem.2008.08.005

12. Chen J, Wu D, He F, Liu M, Wu H, Ding J and Su W, Tetrahedron Lett., 2008, 49(23), 3814-3818; DOI:10.1016/j.tetlet.2008.03.127

13. Surpur M P, Singh P R, Patil S B and Samant S D, Synth Commun., 2007, 37(12), 1965-1970; DOI:10.1080/00397910701354699

14. Dabiri M, Salehi P, Bahramnejad M, Alizadeh M M, Chem., 2010, 141, 877; DOI:10.1007/s00706-010-0341-1

15. Rostamizadeh S, Amani A M, Aryan R, Ghaieni H R nad Shadjou N, Synth Commun., 2008, 38(20), 3567-3576; DOI:10.1080/00397910802178427

16. Zeng LY and Cai C, J Heterocycl Chem., 2010, 47(5), 1035-1039; DOI:10.1002/jhet.414

17. Rambabu D, Kumar S K,Sreenivas B Y, Sandra S, Kandale A, Misra P, Rao M V B, Pal M, Tetrahedron Lett., 2012, 54(6), 495-501; DOI:10.1016/j.tetlet.2012.11.057

18. Ali KN and Panahi F, Green Chem., 2011, 13, 2408-2415; DOI:10.1039/C1GC15360A

19. Ramesh K, Karnakar K, Satish G, Anil Kumar B S P and Nageswar Y V D, Tetrahedron Lett., 2012, 53(51), 6936-6939; DOI:10.1016/j.tetlet.2012.10.029

20. Amberlite IR-120H (Ion exchange Resin) is a sulfonated polystyrene based gel type strongly acidic cation exchange resin. It has excellent physical, chemical and thermal stability and has emerged as an efficient heterogeneous catalyst, see for example: Varghese A, Nizam A, Kulkarni R and George L, amberlite ir-120H. Eur J Chem., 2012, 3(2), 247-252. 